\title{
THE SHEDDING OF THE MUCOSA OF THE BRONCHIAL TREE IN ASTHMA
}

\author{
BY \\ BERNARD NAYLOR* \\ From the Department of Pathology, the University of Michigan, Ann Arbor, Michigan
}

(RECEIVED FOR PUBLICATION JULY 29, 1961)

In this paper a study is reported which indicates conclusively that excessive shedding of epithelium of the lower respiratory tract occurs during life in bronchial asthma, that it occurs especially during asthmatic attacks, and that this phenomenon is seen almost exclusively in this disease.

Other observers have reported that sputa from asthmatics often contain large, well-circumscribed, compact clusters of columnar epithelial cells ; they are quite distinctive. Von Hoesslin (1921) referred to them as Epithelialzellballen, which is a good descriptive term. We have selected the eponym "Creola body," which has the merit of being euphonious and succinct. (Creola was the Christian name of the patient in whose sputum these columnar cell clusters were originally observed in our material.) They were noticed previously by Vierordt (1883), and subsequently by Farber, Wood, Pharr, and Pierson (1957), Carabelli (1958), Cohen and Prentice (1959), and Koss and Durfee (1961). The last four authors believed that they were fragments of mucosa which had become detached because it was hyperplastic, but none of the others offered reasons why they were found in the sputa of asthmatics. After studying their morphology, one has no doubt that they are fragments of shed, though not necessarily hyperplastic, mucosa, of the lower respiratory tract.

If that is what they are, and if shedding of bronchial and bronchiolar mucosa occurs almost exclusively in bronchial asthma, these columnar cell clusters should be found equally exclusively in sputa of asthmatics, and more should be found during attacks of asthma than when the disease is quiescent. The sputa of asthmatics and nonasthmatics have been analysed and compared to find out if this is so.

\section{Material and Method}

A single specimen of sputum from each of 100 asthmatic and 100 non-asthmatic patients was

* Present address : Papanicolaou Cancer Research Institute, 1155 N.W. 14th Street, Miami 36, Florida. examined. The sputa of asthmatics were provided by the allergy section of the Department of Internal Medicine at the University of Michigan Medical Center; the non-asthmatic sputa were consecutive specimens sent to the Cytodiagnostic Laboratory for routine examination for carcinoma cells. (Twenty-five patients had bronchogenic carcinoma.) All were "deep-cough" specimens; if dust-containing phagocytes were not seen in them under the microscope, they were rejected as being saliva, not sputum. Certain clinical data were recorded when each of the asthmatic sputum samples was collected.

Two smears were prepared from each specimen in the manner used for routine cytodiagnosis (Vincent Memorial Hospital, 1950). This method did not give exactly the same volume of sputum on each slide, but it was, when considering the large number of specimens, sufficiently quantitative. After staining by the Papanicolaou method, each smear was covered by a $22 \times 40 \mathrm{~mm}$. coverslip and screened, strip by strip, under the microscope. The number of compact columnar cell clusters was counted in each smear, and the sum in each pair of smears was the figure allotted to that specimen.

The morphological appearance of these peculiar columnar cell clusters will be given before the results are presented. The clusters were well defined, noticeably compact, and some contained over 100 cells (Fig. 1); their shapes were round to serpentine (Fig. 2). The compactness, the cytoplasm which was sometimes vacuolated, the occasional fringe of cilia, and the peripheral palisading of cells were regarded as evidence that they were fragments of ciliated columnar epithelium of the respiratory tract. The clusters were single or in large groups (Fig. 3). At times the clusters appeared to be strips of epithelium with the ends curled up (Fig. 2).

\section{RESULTS}

Forty-two per cent. of asthmatics' but only $3 \%$ of non-asthmatics' sputa contained the columnar cell clusters (Table I). Forty-five per cent. of specimens obtained from patients during attacks of asthma contained columnar cell clusters, in contrast to $31 \%$ in those asthmatics who were not having attacks. (Nearly all those asthmatics 


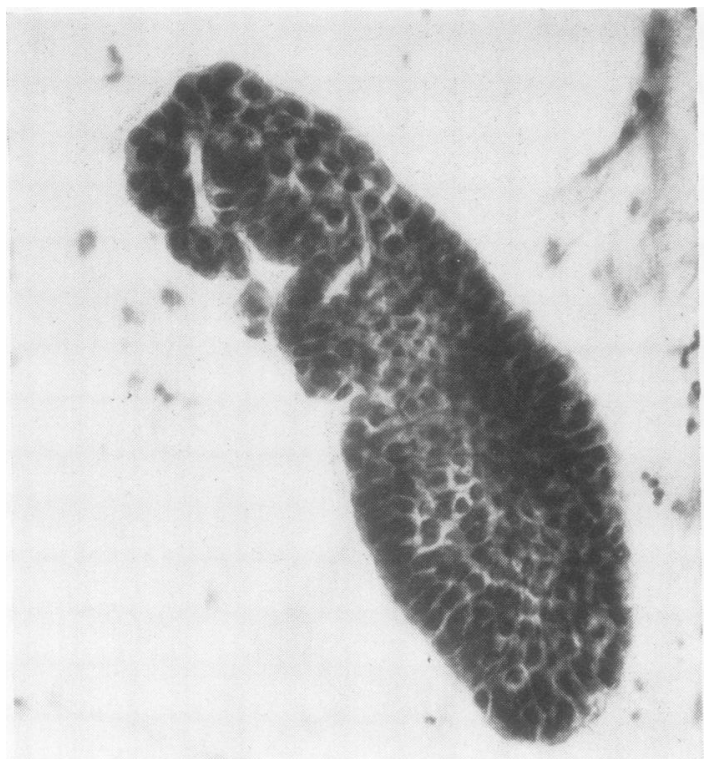

FIG. 1.-A large compact cluster of columnar epithelial cells. Cilia are absent. Notice the peripheral palisading. This cluster contains about 300 cells. (Papanicolaou stain $\times 30$.)

who were stated to be not having an attack when their sputa were collected had had one during the previous week, and undoubtedly, in many of them, there still remained some pathological changes of the acute episode.) What is more striking, how-

\section{TABLE I}

COLUMNAR CELL CLUSTERS IN SPUTUM

\begin{tabular}{llllll}
\hline Asthmatics & $\ldots$ & $\ldots$ & $\ldots$ & $\ldots$ & $42 \%$ \\
Non-asthmatics &. & $\ldots$ & $\ldots$ &. & $3 \%{ }^{*}$
\end{tabular}

* A case each of chronic bronchitis, bronchiectasis, and " cystic disease" of the lung.

ever, is the average number of clusters found in a specimen of each group. During an asthmatic attack this average was 33 (range of 0 to 371), whereas the corresponding figure for those not having an attack at the time of collection was three (range of 0 to 11) (Table II).

TABLE II

COLUMNAR CELL CLUSTERS IN ASTHMATICS' SPUTUM

\begin{tabular}{ll|c|c|c}
\hline & $\begin{array}{c}\text { Percentage } \\
\text { with Columnar } \\
\text { Cell Clusters }\end{array}$ & $\begin{array}{c}\text { Average } \\
\text { Number }\end{array}$ & Range \\
\hline $\begin{array}{lll}\text { During attack } \\
\text { Not during attack }\end{array}$ & $\cdots$ & 45 & 33 & $0-371$ \\
\hline
\end{tabular}

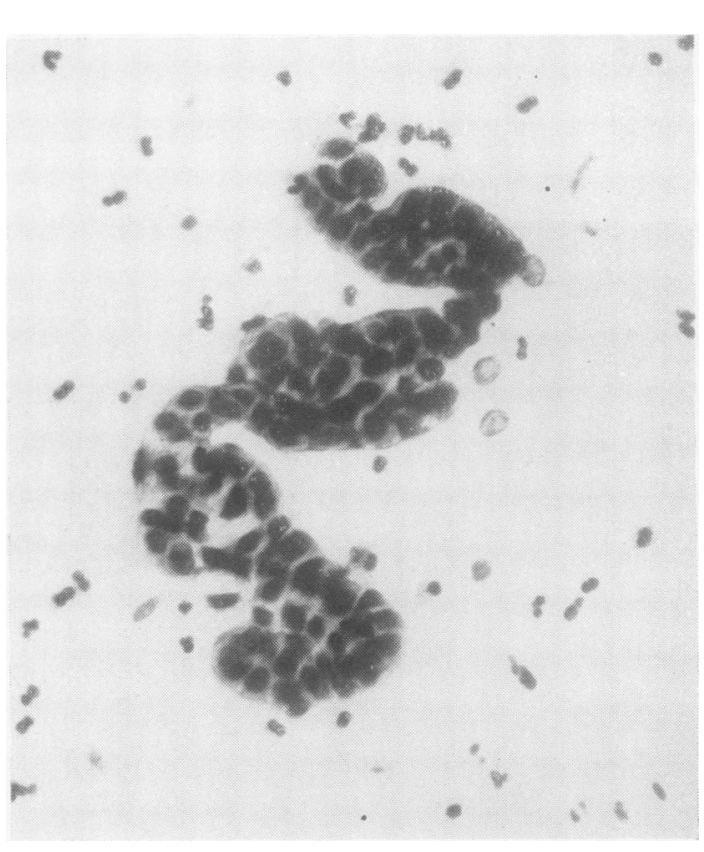

FIG. 2.-A serpentine cluster of columnar epithelial cells. This has the appearance of a strip of columnar epithelium with rolled-up ends. (Papanicolaou stain $\times 33$.)

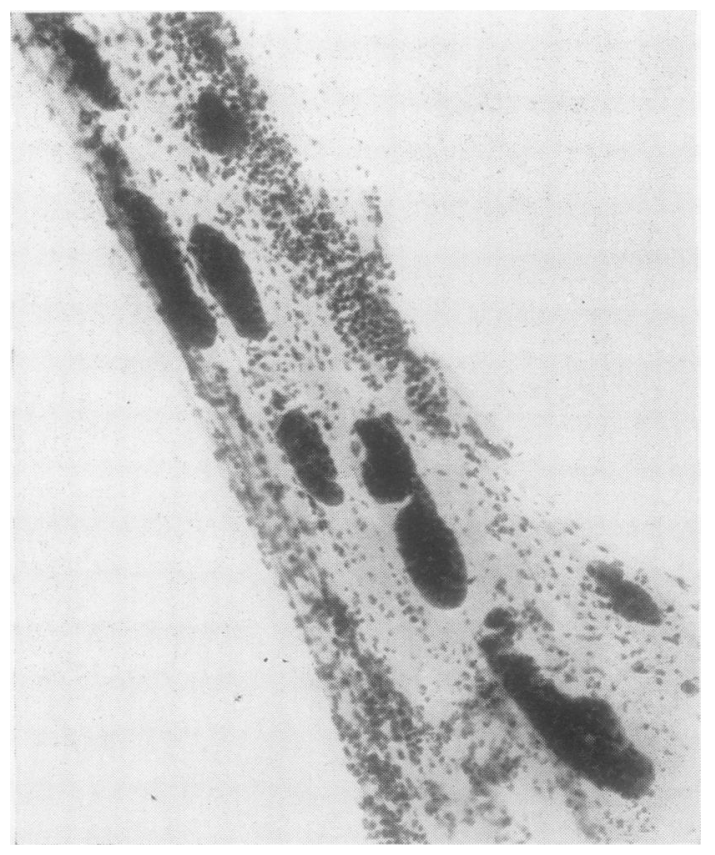

FIG. 3.-Sputum containing many compact columnar cell clusters in one field. (Papanicolaou stain $\times 12$.) 
There was no correlation between the presence of columnar cell clusters in sputa and the type of treatment that the asthmatic patients were given, particularly potassium iodide and corticosteroids.

\section{Discussion}

Shedding of bronchial and bronchiolar epithelium in asthma was described in necropsy specimens over 60 years ago (Fraenkel, 1898, 1900 ), but it is in recent years that this facet of the pathological changes in bronchial asthma has been emphasized, and its significance has been discussed (Houston, De Navasquez, and Trounce, 1953 ; Dunnill, 1960). The photomicrographs of the last-mentioned authors show partial or complete detachment of epithelium of bronchi and bronchioles leaving only a thin, and generally single-celled, layer of basal cells. This detachment was not ascribed to post-mortem artefact for several reasons:

1. The columnar epithelial cells were intimately mixed with the characteristic mucous plugs found in the bronchial tree.

2. Columnar epithelial cells, singly or in groups, sometimes appear in the centre of the exudate in a bronchus with a normal lining mucosa, indicating that they have been carried from another level of the bronchial tree.

3. Thomson (1945) described similar detachment of ciliated epithelium in an ovarian teratoma which contained a respiratory type of epithelium resting on smooth muscle, and which showed the typical "asthmatic" reaction of eosinophilia and thickening of the basement membrane.

4. This detachment had not been seen in the lungs of patients who had died of other conditions.

This analysis of sputa shows, in a more direct manner, that shedding of mucosa of the lower respiratory tract during life is common in asthmatics, especially during attacks, whereas it is extremely uncommon in non-asthmatics. The quantity of sputum on two smears is but a small fraction of the amount cleared from the lower respiratory tract during one day, and consequently the amount of respiratory epithelium shed will be many times greater than that in a single specimen of sputum. When it is considered that in several of our specimens well over 100 columnar cell clusters were counted, it is entirely possible that shedding of columnar epithelium is of great magnitude. An original explanation of this shedding is not offered here; suffice it to say that Dunnill's (1960) explanation, that it is due to subepithelial oedema, seems most reasonable.

It is the failure of clearance of bronchial secretion which is the outstanding feature of the asthmatic lung. The detachment of large amounts of ciliated epithelium may severely hamper the removal of mucus from the lower respiratory tract ; even without this detachment, removal is more difficult because of the viscid quality of the mucus. One might therefore expect that the more columnar cell clusters that are found in a specimen of sputum, the worse the prognosis. Patients who were having asthmatic attacks and who were coughing up columnar cell clusters in their sputa stayed in the hospital after the specimens were obtained on an average three days longer than those patients who were not coughing up these

TABLE III

AVERAGE STAY IN HOSPITAL OF ASTHMATICS AFTER SPUTUM COLLECTION

\begin{tabular}{llll|l}
\hline & & & & Days \\
\hline With columnar cell clusters & $\ldots$ & $\ldots$ & $\ldots$ & 14 \\
Without,, & & 11 \\
With more than 10 columnar cell clusters & $\ldots$ & & 17 \\
\hline
\end{tabular}

clusters (Table III) ; those patients whose smears contained more than ten clusters stayed, on an average, six days longer.

However, there are some contradictory examples, such as a patient whose smears contained 268 clusters, the second highest number in the series; she was discharged from the hospital four days after the specimen was obtained. Two patients died, presumably in status asthmaticus. The smears of one, which were prepared four days before death, contained no columnar cell clusters ; the smears of the other, which were prepared 26 days before death, contained 371 cell clusters, the highest number in the series. The assay of detached respiratory epithelium cannot yet be considered reliable as an index of prognosis in patients having attacks of asthma. More experience is needed with patients who die in status asthmaticus, and more refinement in the selection of the sputum to be smeared, especially regarding the use of identical volumes.

\section{SUMMARY}

The sputa of asthmatics often contain large compact clusters of columnar epithelial cells (Creola bodies) which are a manifestation of 
detachment of the mucosa of the lower respiratory tract. This detachment, as shown by these peculiar columnar cell clusters, is seen almost exclusively in asthmatics, and increases considerably during asthmatic attacks.

This loss of ciliated columnar epithelium may be of great magnitude. There is evidence that it hinders recovery from asthmatic attacks, and may be a factor leading to death.

I gratefully acknowledge the help of Dr. J. M. Sheldon and Dr. J. A. McLean, of the Department of Internal Medicine, who provided the sputa and clinical data of the asthmatics.

\section{REFERENCES}

Carabelli, A. A. (1958). Amer. Rev. Tuberc.. 77, 22.

Cohen, R. C., and Prentice, A. I. D. (1959). Tubercle (Lond.), 40, 44. Dunnill, M. S. (1960). J. clin. Path., 13, 27.

Farber, S. M., Wood, D. A., Pharr, S. L., and Pierson, B. (1957). Dis. Chest, 31, 1.

Fraenkel, A. (1898). Z. klin. Med., 35, 559.

- (1900). Dtsch. med. Wschr., 26, 269.

Hoesslin, H. von (1921). Das Sputum. Springer, Berlin.

Houston, J. C., Dz Navasquez, S., and Trounce. J. R. (1953). Thorax, 8, 207.

Koss, L. G.. and Durfee, G. R. (1961). Diagnostic Cytology and its Histopathologic Bases. Lippincott, Philadelphia.

Thomson, J. G. (1945). J. Path. Bact., 57, 213.

Vierordt, O. (1883). Berl. klin. Wschr.. 20, 437.

Vincent Memorial Hospital (1950). The Cvtologic Diagnosis of Cancer, by the Staff of the Vincent Memorial Laboratory. Saunders, Philadelphia. 